\title{
Spectrophotometric Determination of Iodate in Table Salt
}

\author{
Rosa Lina G.N P. Silva ${ }^{a}$, A. Fernando de Oliveira ${ }^{b}$, \\ and Eduardo Almeida Neves ${ }^{b}$ * \\ ${ }^{a}$ Departamento de Química da Universidade Federal do Piaui, Teresina - Piauí, Brazil \\ ${ }^{b}$ Departamento de Química da Universidade Federal de São Carlos, \\ Via Washington Luiz, km 235, 13565-905 São Carlos - SP, Brazil
}

Received: July 3, 1997

\begin{abstract}
Iodato de Potássio em sal de cozinha pode ser determinado espectrofotometricamente no UV em dois máximos no espectro de absorção bem definidos (288 e $352 \mathrm{~nm}$ ) após ser convertido à espécie $\mathrm{I}_{3}{ }^{-}$por reação com iodeto na presença de ácido fosfórico. Curvas de calibração com coeficientes angulares de $7.320 \times 10^{4}$ e $1.103 \times 10^{5} \mathrm{~L} \mathrm{~mol}^{-1} \mathrm{~cm}^{-1}$ foram obtidas a 352 e $288 \mathrm{~nm}$, respectivamente a $22^{\circ}$. Resultados de $37.39( \pm 0.15)$ e $63.67( \pm 0.16) \mathrm{mg}$ de $\mathrm{KIO}_{3}$ por $\mathrm{kg}$ se sal foram obtidos com massas de $0.15-0.21 \mathrm{~g}$, comparáveis aos resultados da titulação iodométrica que utiliza grandes quantidades de amostras (20-50 g). O método tem sido adequado para testar a homogeneidade de distribuição do iodo no sal de cozinha, já que pequenas quantidades de amostras são utilizadas.
\end{abstract}

Potassium iodate in table salt can be spectrophotometrically determined at two well defined UV absorption maxima ( 288 and $352 \mathrm{~nm}$ ), after being converted to $\mathrm{I}^{-}$by reaction with iodide in the presence of phosphoric acid Calibration curves with slopes of $7.320 \times 10^{4}$ and $1.103 \times 10^{5} \mathrm{~L} \mathrm{~mol}^{-1}$

$\mathrm{cm}^{-1}$ were obtained at 352 and $288 \mathrm{~nm}$, respectively, at $22^{\circ} \mathrm{C}$. Typical results of $37.39( \pm 0.15)$ and $63.67( \pm 0.16) \mathrm{mg} \mathrm{KIO}_{3}$ per $\mathrm{kg}$ of salt were obtained with samples of $0.15-0.21 \mathrm{~g}$, comparable with results from a standard but less precise iodometric titration of large samples (20-50 g). The method has been found adequate for checking homogeneity of iodine distribution in table salt, as small weighed samples are normally required.

Keywords: iodized salt, spectrophotometry, salt, iodate

\section{Introduction}

In order to control the main cause of endemic goitre, specially for inhabitants of mountainous areas in several regions of the world, the addition of some form of iodine to common salt for human consumption became an universal practice. The World Health Organization recommends an addition of $10 \mathrm{mg}$ of the element to $1 \mathrm{~kg}$ of table salt (10 ppm). In some countries this procedure is not only optional but a legal obligation. In the U.S.A. iodized salt has $100 \mathrm{mg} \mathrm{kg}^{-1}$ of iodine, while in Switzerland the value is $5 \mathrm{mg} \mathrm{kg}^{-1}$. In Brazil the iodine content is officially controled in commercial products and should fall in the range of $10-30 \mathrm{mg} \mathrm{kg}^{-1}$ of the element in table salt, as potassium iodate. It is also desirable that the iodine distribution in salt for human consumption be as homogeneous as possible. It is not possible to measure the latter parameter using the less sensitive titration method, usually applied for the element determination ${ }^{1}$.

In spite of controversies about such addition, sodium or potassium iodide was formerly added to salt as the source of the element. However, the recognition that the oxidation of iodide to iodine was possible during salt treatments and long storage, with eventual losses of the element, lead to the current use of potassium iodate for this purpose, due to its high chemical stability in a neutral or alkaline medium. In fact, iodide is thermodynamically unstable in sea water, especially in the presence of light and dissolved oxygen ${ }^{2}$. Measurement of the average content of iodate in food grade salt is normally performed iodometrically, by titrating, with $5 \times 10^{-3} \mathrm{~mol} \mathrm{~L}^{-1}$ thiosulphate, the iodine released by reaction between iodate and iodide ions in acidic medium, from 
large samples of salt $(20-50 \mathrm{~g})^{1}$. Alternative sensitive procedures are found in the literature on the basis of mixed techniques involving iodate reduction followed by extraction and spectroelectrochemical measurements ${ }^{3}$, on the basis of the catalytic effect on the classic $\mathrm{Ce}$ (IV)/As(III) system $^{4,5}$ by ion-pair chromatography ${ }^{6}$ and the indirect spectrophotometric method ${ }^{7}$. All these procedures do not seem adequate for routine analysis as they require several cumbersome steps of sample treatments and/or they are not very precise, although sensitive.

A new alternative, sensitive and easy to perform spectrophotometric method is herein presented for determination of iodate in salt. As it requires small amounts of salt in the working solution (0.1-0.2 g), it is particularly useful for determining the homogeneity of the distribution of iodate in a commercial sample.

\section{Experimental}

All reagents were of A.R. specification(Merck, Carlo Erba): sodium chloride, iodine, potassium iodate, sodium hydroxide, sodium tiosulphate and acids. Commercial table salts were tested during the development of the analytical method.

Solutions were prepared with deionized and subsequently distilled water and made up to the desired volume in first class volumetric flasks.

Measurements were carried out using a Hewlett Packard $8452 \mathrm{~A}$ spectrophometer with a $1 \mathrm{~cm}$ light path quartz cuvette, at room temperature, $22{ }^{\circ} \mathrm{C}$. The Origin 3.5 software from Microsoft was used for developing calibration curves and the regression parameters of the linear plots.

The following solutions were used in the spectrophotometric procedures:

Solution 1: $0.2140 \mathrm{~g}$ of the primary standard potassium iodate (dried in an oven to $110^{\circ} \mathrm{C}$ ) were made up to $100 \mathrm{~mL}$ in a volumetric flask in order to obtain a $0.0100 \mathrm{~mol} \mathrm{~L}^{-1}$ solution. This solution was diluted in order to obtain a final standard iodate solution of $1.000 \times 10^{-5} \mathrm{~mol} \mathrm{~L}^{-1}$, to be used in the calibration curve.

Solution 2: $5.00 \mathrm{~g}$ of sodium chloride were made up to a volume of $50 \mathrm{~mL}$.

Solution 3: $3.32 \mathrm{~g}$ of potassium iodide (iodate free as checked by acidification) were made up to a volume of $100 \mathrm{~mL}$, including $1 \mathrm{~mL}$ of $0.1 \mathrm{~mol} \mathrm{~L}^{-1}$ sodium hydroxide.

Solution 4: $11.5 \mathrm{~g}$ of phosphoric acid (85\%) were made up to a volume of $100 \mathrm{~mL}$ to obtain a $1.0 \mathrm{~mol} \mathrm{~L}^{-1}$ solution.

Solution 5: (Blank 1 solution) $2.0 \mathrm{~mL}$ of solution 2 plus 1.0 $\mathrm{mL}$ of solution 4 were made up to a volume of $10 \mathrm{~mL}$ in a volumetric flask.

Solution 6A: (Sample solution) About $1 \mathrm{~g}$ of the salt was made up to a volume of $25 \mathrm{~mL}$, for checking homogeneity of the product.

Solution 6B: (Sample solution) About $100 \mathrm{~g}$ of the salt were made up to $500 \mathrm{~mL}$ for analysing the average iodate content, and comparing of methods.
Solution 7: (Blank 2 solution) 4-7 mL of solution $6 \mathrm{~A}$ or $6 \mathrm{~B}$ plus $1.0 \mathrm{~mL}$ of solution 4 were made to a volume of $10 \mathrm{~mL}$ in a volumetric flask.

Procedure 1. Calibration curve. 1-6 mL of the standard iodate solution $\left(1.000 \times 10^{-5} \mathrm{~mol} \mathrm{~L}^{-1}\right)$ were pipetted into $10 \mathrm{~mL}$ volumetric flasks with $1 \mathrm{~mL}$ of solution $3,2.0 \mathrm{~mL}$ of solution 2 and finally $1 \mathrm{~mL}$ of phosphoric acid. The volumes were made up and the absorbances at the desired wavelength (288 and/or $352 \mathrm{~nm}$ ) vs. the blank, solution 5, were measured. $1 \mathrm{~cm}$ light path cuvettes were used. The parameters of the linear plot of $\mathrm{A} v s$. $\left[\mathrm{IO}_{3}{ }^{-}\right]$or $[\mathrm{I}]$ were determined.

Procedure 2. Sample analysis. 4-7 $\mathrm{mL}$ of solution $6 \mathrm{~A}$ or $6 \mathrm{~B}$, or $0.2 \mathrm{~g}$ of the salt, plus $1 \mathrm{~mL}$ solution 3 and $1 \mathrm{~mL}$ solution 4 were made up to $10 \mathrm{~mL}$. Absorbances at 288 or $352 \mathrm{~nm}$ vs. blank 2 (solution 7), containing the same salt solution were measured.

$\mathrm{C}$ is the concentration of potassium iodate or iodine in $\mathrm{mg} \mathrm{kg}^{-1}$ of salt and was calculated by the following formula:

$$
\mathrm{C}=\frac{1000 \mathrm{~A} \mathrm{~W} \mathrm{~V} \mathrm{~V}_{3}}{\mathrm{~b} \varepsilon \mathrm{V}_{2} \mathrm{~m}}
$$

where $\mathrm{A}$ is the absorbance at the desired wavelength with the corresponding molar absorptivity $\varepsilon$ (see Table 1 ); $\mathrm{W}$ is the mol of potassium iodate, $214.0 \mathrm{~g}$ or the mol of iodine, $126.9 \mathrm{~g}, \mathrm{~b}$ is the light path, $1 \mathrm{~cm}$; $\mathrm{m}$ in $\mathrm{g}$ is the sample of salt weighed out and made up to a $\mathrm{V}_{1} \mathrm{~mL}$ volumetric flask (see solutions 6A and 6B); $\mathrm{V}_{2}$ is the volume of $4-7 \mathrm{~mL}$ pipetted into the $\mathrm{V}_{3}$ volumetric flask, usually $10 \mathrm{~mL}$, in order to prepare the working solution.

Titration Procedure. For the conventional procedure ${ }^{1}$, $40 \mathrm{~g}$ of the salt or $50 \mathrm{~mL}$ of a solution containing $200 \mathrm{~g} \mathrm{~L}^{-1}$ of the salt $(6 \mathrm{~B})$ were used. The salt solution was treated with $10 \mathrm{~mL}$ of solution 3 and $10 \mathrm{~mL}$ of solution 4 . The released iodine was titrated with a $0.005 \mathrm{~mol} \mathrm{~L}^{-1}$ standard thiosulphate, with addition of $1 \mathrm{~mL}$ of starch indicator, $1 \%$ solution, near the end point.

\section{Results and Discussion}

Figure 1 shows the spectral characteristics of iodine with maxima at $288 \mathrm{~nm}$ and $352 \mathrm{~nm}$ and a minimum at 320 $\mathrm{nm}$, in the presence of excess iodide and in acidic medium in order to avoid disproportionation of the halogen by reaction with water. In spite of the higher sensitivity presented, this strong spectral band appears only in the presence of iodide and can be attributed to the formation of $\mathrm{I}_{3-}$. Although the peak observed at $288 \mathrm{~nm}$ presents greater sensitivity, the peak at $352 \mathrm{~nm}$ has been used to measure the iodine released from the reaction of ozone with iodide ions $^{8,9}$. Other spectrophotometric measurementes of the species $\mathrm{I}_{3}{ }^{-}$are based on the blue color developed in the presence of $\operatorname{starch}^{10,11}$. In spite of the possibility of measuring the deep blue iodine/starch mixed species at the 
Table 1. Comparison between spectrophotometric and titrimetric methods for the analysis of two commercial iodized salts. Average results in $\mathrm{mg} \mathrm{kg}^{-1}$ from seven determinations; $95 \%$ confidence level are shown.

\begin{tabular}{|c|c|c|c|c|}
\hline $\begin{array}{l}\text { SALT I } \\
\text { Fine crystals }\end{array}$ & $\begin{array}{c}288 \mathrm{~nm} \\
\varepsilon=1.103 \times 10^{5} \\
\mathrm{~L} \mathrm{~mol}^{-1} \mathrm{~cm}^{-1}\end{array}$ & $\begin{array}{c}352 \mathrm{~nm} \\
\varepsilon=7.320 \times 10^{4} \\
\mathrm{~L} \mathrm{~mol}^{-1} \mathrm{~cm}^{-1}\end{array}$ & $\begin{array}{c}288+352 \mathrm{~nm} \\
\varepsilon=1.835 \times 10^{5} \\
\mathrm{~L} \mathrm{~mol}^{-1} \mathrm{~cm}^{-1}\end{array}$ & Iodimetric titration \\
\hline Potassium iodate & $37.79 \pm 0.09$ & $37.93 \pm 0.21$ & $37.85 \pm 0.16$ & $37.80 \pm 0.26$ \\
\hline Iodine & $22.41 \pm 0.09$ & $22.50 \pm 0.12$ & $22.44 \pm 0.10$ & $22.42 \pm 0.15$ \\
\hline \multicolumn{5}{|l|}{ Absorbances } \\
\hline $1 \mathrm{~cm}$ light path & $0.3894 \pm 0.0015$ & $0.2595 \pm 0.0014$ & $0.6390 \pm 0.0028$ & \\
\hline \multicolumn{5}{|l|}{$\begin{array}{l}\text { SALT II } \\
\text { Coarse crystals }\end{array}$} \\
\hline Potassium iodate & $63.55 \pm 0.12$ & $63.67 \pm 0.16$ & $63.59 \pm 0.09$ & $63.60 \pm 0.37$ \\
\hline Iodine & $37.68 \pm 0.06$ & $37.75 \pm 0.10$ & $37.71 \pm 0.05$ & $37.71 \pm 0.22$ \\
\hline \multicolumn{5}{|l|}{ Absorbances } \\
\hline $1 \mathrm{~cm}$ ligth path & $0.6549 \pm 0.0012$ & $0.4355 \pm 0.0011$ & $1.0904 \pm 0.0016$ & \\
\hline
\end{tabular}

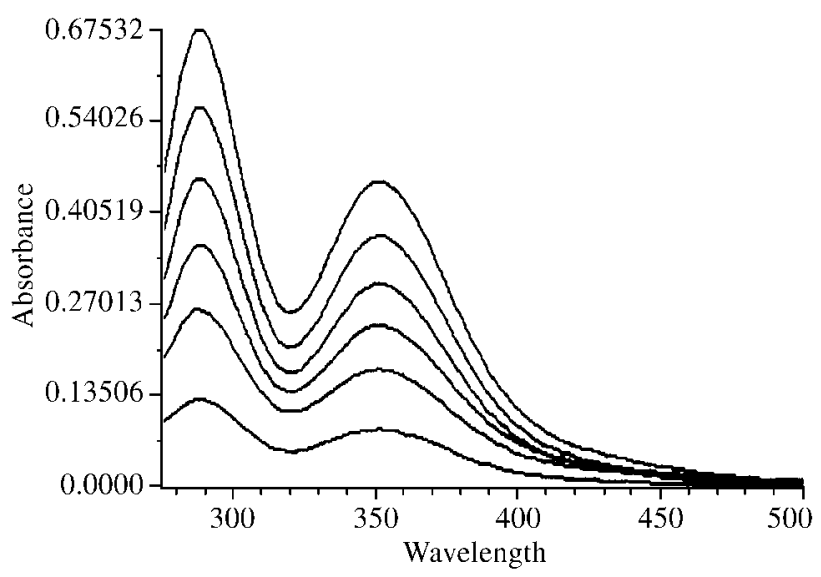

Figure 1. Spectral characteristics of released iodine with maxima at 288 $\mathrm{nm}$ and $352 \mathrm{~nm}$ and a minimum at $320 \mathrm{~nm}$ in the presence of $0.020 \mathrm{~mol}$ $\mathrm{L}^{-1}$ of iodide and $0.010 \mathrm{~mol} \mathrm{~L}^{-1}$ phosphoric acid. Iodate concentrations from 1 to $6 \mu \mathrm{mol} \mathrm{L}$.

visible part of the spectrum $(588 \mathrm{~nm})$, some preliminary experiments led us to discard this procedure for iodate/iodine determination in salt. In fact, the color development and color stability of working solutions depend on several parameters such as the starch sample, the concentration and stability of the solution, the acidity, the salting out effects of electrolytes and a number of unexpected factors that can markedly affect the precision of measurements. Thus, it has been found more convenient to develop the procedure on the basis of the more favorable ultra violet measurements of the released iodine.

Figure 2 shows that in the range of $0.01-0.025 \mathrm{~mol} \mathrm{~L}^{-1}$ of iodide, the absorbances at the peaks reach virtually constant values, due to the well known $\mathrm{I}_{3}$ - formation. Thus, the $0.020 \mathrm{~mol} \mathrm{~L}^{-1}$ iodide concentration was used in the development of calibration curves for analytical purposes. Iodide solution in the presence of $10^{-3} \mathrm{~mol} \mathrm{~L}^{-1}$ sodium hydroxide is highly stable, even in the presence of air: virtually no free iodine was found from spectrophotometric measurements made after 1 month, $v$ s the freshly prepared solution after acidification. However the neutral iodide solution is less stable and should not be used in the working solutions, after storing for more than one week.

Preliminary experiments have also shown that the presence of chloride has a slight supressing effect on the measured absorbances, which has been found to be constant in the range of $0.180-0.500 \mathrm{~mol} \mathrm{~L}^{-1}$ sodium chloride.

The iodide/iodine system has been found to follow the Lambert-Beer's law at three wavelengths with the following indirect molar absorptivities for iodate in $\mathrm{L} \mathrm{mol}^{-1} \mathrm{~cm}^{-1}$ in the presence of $0.020 \mathrm{~g} \mathrm{~L}^{-1}$ potassium iodide, 0.200 mol L $\mathrm{L}^{-1}$ phosphoric acid and $20 \mathrm{~g} \mathrm{~L}^{-1}$ sodium chloride: $1.103 \times 10^{5}$ at $288 \mathrm{~nm}, 7.320 \times 10^{4}$ at $352 \mathrm{~nm}$ and $3.980 \times 10^{4}$ at $320 \mathrm{~nm}$, the latter being the minimum between the two peaks. The sum of spectral measurementes at 288 and $352 \mathrm{~nm}$ provides an even higher sensitivity for iodate, with a slope of $1.835 \times 10^{5} \mathrm{~L} \mathrm{~mol}^{-1} \mathrm{~cm}^{-1}$ for the calibration curve.

The high sensitivity for the indirect determination of iodate is three times that expected for the $\mathrm{I}_{3}{ }^{-}$species due to the following redox reaction:

$$
\mathrm{IO}_{3^{-}}+5 \mathrm{I}^{-}+6 \mathrm{H}^{+} \longrightarrow 3 \mathrm{H}_{2} \mathrm{O}+3 \mathrm{I}_{2}
$$

As the added element in salt now occurs only as potassium iodate, the above redox reaction and calibration curves are adequate for the determination of the iodine 


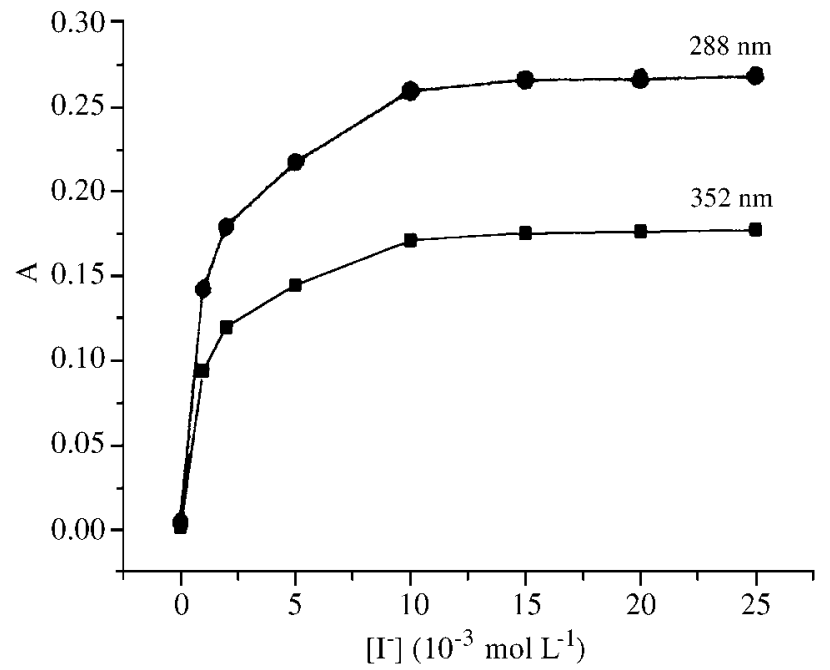

Figure 2. The effect of iodide concentration on the absorbance of $7.4 \mu \mathrm{mol} \mathrm{L}^{-1}$ iodine in $0.010 \mathrm{~mol} \mathrm{~L}^{-1}$ phosphoric acid.

element in the commercial product without the need for previous oxidation of iodide.

The best condition for analytical work with the above calibration curve is to measure at $288 \mathrm{~nm}$. However, other analytical calibration curves can be used depending on the sensitivity required for the sample. In fact, the best analytical results are obtained from measuring absorbance near the most precise condition, about 0.43 (36.7\% transmittance). Thus, these calibration curves at 288 and $352 \mathrm{~nm}$ (and 352 plus $288 \mathrm{~nm}$ ) with diverse slopes (molar absorptivities) encompass a wide range of iodate concentrations in salts. The identification limit is estimated as being $2.0 \times 10^{-7} \mathrm{~mol} \mathrm{~L}^{-1}$ for iodate, with $1 \mathrm{~cm}$ light path cuvettes. Many experiments have shown that, for the range of 30-70 $\mathrm{mg} \mathrm{kg}{ }^{-1}$ potassium iodate, $10 \mathrm{~mL}$ working solutions containing about $0.2 \mathrm{~g}$ of salt are adequate for analytical work.

Preliminary studies with acidification with sulphuric, phosphoric and acetic acid, gave virtually the same results. The preference for the use of phosphoric acid in the working solutions is that it can complex traces of iron(III), possibly present in salt samples, thereby reducing the tendency to oxidise iodide to iodine. However, the presence of iron(III) in commercial products of the present study was not detected in qualitative tests with thiocyanate.

Table 1 presents the average of seven analytical results for the iodate/iodine content from solutions prepared with two table salts normally sold in Brazilian supermarkets. Salt I is a higher quality finely ground product and contains some solid additives such as silica and calcium silicates to make it less hygroscopic. When dissolved in water it presents some turbidity which is compensated for in the spectrophotometric measurements with the blank; the filtered solution gave virtually the same analytical result. Salt II is a less refined product, in the form of coarse crystals, without solid additives. In order to make comparisons with the less sensitive titrimetric procedure, large $500 \mathrm{~mL}$ solutions were prepared with a salt content of $200 \mathrm{~g} \mathrm{~L}^{-1} ; 50 \mathrm{~mL}$ aliquots of these solutions were used in titrations with thiosulphate. A normal procedure for the average iodate content was performed with $20-50 \mathrm{~g}$ of salt.

The final results in Table 1 show very good agreement between the spectrophotometric measurements and the iodimetric titrimetric method, with higher precision for the the former method, using three different calibration curves.

It is interesting to show that the distribution of iodate in the commercial products is not homogeneous. The analysis of iodate from $1 \mathrm{~g}$ random samples (see Experimental section, solution 6B) shows a relative standard deviation of $3.3 \%$ for salt I and $16 \%$ for salt II. These deviations are considerably larger than those for these salts shown in Table 1 and are related to the salt refining process. During the salt treatment an iodate solution is sprayed onto huge amounts of the wet salt, followed by mixing and drying. The fine ground salt I has a more homogeneous iodate distribution due to an additional milling process, which enhances the iodate distribution. The titration procedure makes this lack of homogeneity less evident due to the fact that it requires samples of at least $20 \mathrm{~g}$ in order to analyse the iodate content.

\section{Acknowledgments}

The authors are grateful to $\mathrm{CNPq}$ for support and CAPES/PICD (Brazilian Foundations) for a grant.

\section{References}

1. Williams, S. ed. In Official Methods of Analysis, $14^{\text {th }}$ ed., Association of Official Analytical Chemists, Arlington, U.S.A., 1984, p. 637.

2. Huang, C.P.; O'Melia, C.R.; Morgan, J.J. eds. In Aquatic Chemistry, American Chemical Society, Washingtton DC, 1995, pgs.135-139.

3. Fan, Y.Z.; Jiang, J.C.; Bai, Z.P.I. Fenxi-Shiyanshi 1996, $15,10$.

4. Toledano, M.; Gutierrez, M.C.; Gomez Hens, A.; Perez Bendito, D. Analysis 1989, 17, 514.

5. Timotheou Potamia, M.M.; Hadjiioannou, T.P.; Mikrochim. Acta II, 1983, 59.

6. Luckas, B. Dtsch.-Lebensm.-Rundsch. 1986, 82, 357.

7. Gonzalez-Diaz, V.; Tallo-Gonzalez C.R.; Garcia Montelongo, F. Analyst 1981, 106, 1224.

8. Byers, D.H.; Saltzman, B.E. J. Am. Indust. Hyg. Assoc. 1958, 19, 251.

9. Lodge Jr, J.P. ed. In Methods of Air Sampling and Analysis, 3rd ed., LewisInc., Chelsea, Michigan, U.S.A.,1989, p. 403.

10. Lambert, J.L. Anal.Chem.1951, 23, 1251.

11. Marczenco, Z. Spectrophotometric Determination of Elements, John Wiley \& Sons Inc., N. York, London, 1976, p.297. 